\title{
Babesia microti Immunoreactive Rhoptry-Associated Protein-1 Paralogs Are Ancestral Members of the Piroplasmid-Confined RAP-1 Family
}

\author{
Reginaldo G. Bastos ${ }^{1, *} * \mathbb{D}$, Jose Thekkiniath ${ }^{2}$, Choukri Ben Mamoun ${ }^{3}$, Lee Fuller ${ }^{2}$, Robert E. Molestina ${ }^{4}$, \\ Monica Florin-Christensen ${ }^{5,6} \oplus^{(}$, Leonhard Schnittger ${ }^{5,6} \oplus^{(}$, Heba F. Alzan ${ }^{1,7,8}$ (i) $_{\text {and Carlos E. Suarez }}{ }^{1,9, *}$ \\ check for \\ updates \\ Citation: Bastos, R.G.; Thekkiniath, \\ J.; Ben Mamoun, C.; Fuller, L.; \\ Molestina, R.E.; Florin-Christensen, \\ M.; Schnittger, L.; Alzan, H.F.; Suarez, \\ C.E. Babesia microti Immunoreactive \\ 1 Department of Veterinary Microbiology and Pathology, College of Veterinary Medicine, \\ Washington State University, Pullman, WA 99164, USA; heba.alzan@wsu.edu \\ 2 Fuller Laboratories, 1312 East Valencia Drive, Fullerton, CA 92831, USA; \\ jose.thekkiniath@fullerlabs.net (J.T.); Lee.Fuller@fullerlabs.net (L.F.) \\ 3 Section of Infectious Diseases, Department of Internal Medicine, Yale School of Medicine, \\ New Haven, CT 06520, USA; choukri.benmamoun@yale.edu \\ 4 Protistology Laboratory, American Type Culture Collection, Manassas, VA 10801, USA; rmolestina@atcc.org \\ 5 Consejo Nacional de Investigaciones Científicas y Técnicas (CONICET), Buenos Aires C1033AAJ, Argentina; \\ jacobsen.monica@inta.gob.ar (M.F.-C.); schnittger.leonhard@inta.gob.ar (L.S.) \\ 6 Instituto de Patobiología Veterinaria, CICVyA, INTA-Castelar, Hurlingham, \\ Buenos Aires C1033AAE, Argentina \\ 7 Parasitology and Animal Diseases Department, National Research Center, Dokki, Giza 12622, Egypt \\ 8 Tick and Tick-Borne Disease Research Unit, National Research Center, Dokki, Giza 12622, Egypt \\ 9 Animal Disease Research Unit, United States Department of Agricultural-Agricultural Research Service, \\ Pullman, WA 99164, USA \\ * Correspondence: reginaldo_bastos@wsu.edu (R.G.B.); carlos.suarez@usda.gov (C.E.S.)
} Rhoptry-Associated Protein-1 Paralogs Are Ancestral Members of the Piroplasmid-Confined RAP-1 Family. Pathogens 2021, 10, 1384. https://doi.org/10.3390/ pathogens 10111384

Academic Editors: Estrella Montero, Jeremy Gray, Cheryl Ann Lobo and Luis Miguel González

Received: 17 September 2021

Accepted: 23 October 2021

Published: 26 October 2021

Publisher's Note: MDPI stays neutral with regard to jurisdictional claims in published maps and institutional affiliations.

Copyright: (C) 2021 by the authors. Licensee MDPI, Basel, Switzerland. This article is an open access article distributed under the terms and conditions of the Creative Commons Attribution (CC BY) license (https:/ / creativecommons.org/licenses/by/ $4.0 /)$.

\begin{abstract}
Babesia, Cytauxzoon and Theileria are tick-borne apicomplexan parasites of the order Piroplasmida, responsible for diseases in humans and animals. Members of the piroplasmid rhoptryassociated protein-1 (pRAP-1) family have a signature cysteine-rich domain and are important for parasite development. We propose that the closely linked B. microti genes annotated as BMR1_03g00947 and BMR1_03g00960 encode two paralogue pRAP-1-like proteins named BmIPA48 and Bm960. The two genes are tandemly arranged head to tail, highly expressed in blood stage parasites, syntenic to rap-1 genes of other piroplasmids, and share large portions of an almost identical $\sim 225$ bp sequence located in their $5^{\prime}$ putative regulatory regions. BmIPA48 and Bm960 proteins contain a N-terminal signal peptide, share very low sequence identity $(<13 \%)$ with pRAP-1 from other species, and harbor one or more transmembrane domains. Diversification of the piroplasmid-confined prap-1 family is characterized by amplification of genes, protein domains, and a high sequence polymorphism. This suggests a functional involvement of pRAP-1 at the parasite-host interface, possibly in parasite adhesion, attachment, and/or evasion of the host immune defenses. Both BmIPA48 and Bm960 are recognized by antibodies in sera from humans infected with B. microti and might be promising candidates for developing novel serodiagnosis and vaccines.
\end{abstract}

Keywords: Babesia microti; BmIPA48; BMR1_03g00960; piroplasmid rhoptry-associated protein-1 (pRAP-1); human babesiosis

\section{Introduction}

Babesia, Cytauxzoon and Theileria are tick-borne apicomplexan piroplasmid parasites of vertebrates that invade and reproduce asexually in erythrocytes. These parasites are a major concern to human and animal health and cause an important economic burden worldwide. Babesia parasites are responsible for acute and persistent hemolytic disease in several wild and domestic vertebrate species, including human. While Theileria parasites are transmitted transstadially by ticks, sensu stricto (s.s.) Babesia spp. are transovarially and, 
in some species, also transstadially, transmitted. Other piroplasmids, such as B. microti, are defined as sensu lato (s.l.) Babesia parasites, based on their transstadial mode of transmission and the absence of schizont stages in their life cycles [1-3].

Human babesiosis is an emergent worldwide zoonosis caused by several Babesia spp., including the s.s. B. divergens and the s.1. B. microti, the latter of which is the predominant agent in the Northeastern and Midwest regions of the US [4,5]. As for other piroplasmids, the life cycle of $B$. microt $i$ is dixenic, involving an invertebrate definitive host and a vertebrate host. In the US, the primary vertebrate host is the white-footed mouse (Peromyscus leucopus) and the invertebrate host is a tick of the genus Ixodes, such as I. scapularis. However, humans are accidental and dead-end hosts when bitten by infected ticks. Importantly, human-to-human transmission of B. microti may occur via contaminated blood transfusions [6,7]. Due to climate change and human activity, the geographic distribution of $I$. scapularis, and hence of B. microti, is expanding rapidly in the US [8]. In addition, the finding of vertical transmission in the white-footed mouse indicates a potentially relevant way of parasite dissemination without the participation of the tick vector [9]. The disease caused by $B$. microti in humans may vary from asymptomatic or subclinical to acute and chronic manifestations, which can be lethal in immunocompromised patients. Clinical manifestations of acute human babesiosis include fever, hemolytic anemia, acute respiratory distress and multiorgan dysfunction [10]. Because of the expansion of the tick habitat and the constant increase in cases of human babesiosis in the US, there is a need to develop vaccines and improved diagnostics against $B$. microti, which requires identification of conserved immunogenic proteins in this apicomplexan parasite.

Apicomplexan parasites, including B. microti, are equipped with an apical complex with at least three distinct secretory organelles known as the rhoptries, micronemes, and spherical bodies or dense granules. These organelles play an essential role in host cell invasion by the parasite [11]. Once the parasite is committed to invasion, it is quickly and actively propelled inside the target cell by the activity of an actin motor, with intervention of the cytoskeletal structures of the parasite [12]. Rhoptry proteins are probably involved in the formation of the parasitophorous vacuole (PV), a membranous structure separating the parasite from the cytoplasm of the host cell, that disappears quickly upon invasion in Babesia parasites [13]. Remarkably, B. microti also developed a mechanism for vesiclemediated antigen export generating an interlacement of vesicles which extends from the plasma membrane of the parasite into the cytoplasm of the host erythrocyte [14]. Few rhoptry proteins have been so far identified and characterized in Babesia parasites. Initial studies performed mainly in B. bovis and B. bigemina were focused on the functional role of rhoptry-associated protein-1s (RAP-1s), which were later identified in all piroplasmids, including other Babesia spp., Theileria spp. and Cytauxzoon felis [15-23]. We hereby refer to these proteins as piroplasmid RAP-1s (pRAP-1s). It is possible that the function of these piroplasmid-specific proteins is needed to support unique features of the parasite life cycle, such as parasite-attachment to the erythrocyte, dissolution of the PV in Babesia, the zippermediated invasion of Theileria, or other events that may be related to erythrocyte invasion and egress [24,25]. The prap-1 gene superfamily encodes the paralogs rap-1 and RAP-1related antigens ( $r r a$ ) in B. bovis [26]. Plasmodial RAP-1 shares the same denomination with pRAP-1s, but they are unrelated non-homologous proteins [27]. Since pRAP-1 proteins are highly immunogenic and can be targeted for neutralization-sensitive antibodies, they may be attractive candidates for diagnostic assays or subunit vaccines against Babesia and Theileria parasites [16,28-34].

The piroplasmid-specific RAP-1 family domain (PF03085) contains a characteristic motif of four cysteine (Cys) residues and a single conserved tyrosine (Tyr) residue. Other definitions of the members of this protein family are based on localization or function, which are still waiting experimental confirmation. Although the pRAP-1 proteins have been identified and annotated in genomes of Babesia spp. s.s., Cytauxzoon felis, and Theileria spp. parasites, they remain not fully identified in the genome of the s.l. parasite B. microti. A RAP putative protein (XP_021337499) was annotated in the genome of B. microti, but this 
protein, which is homologous to Plasmodium and Toxoplasma RAPs, lacks the characteristic motifs of the members of the Babesia/Theileria pRAP-1 superfamily [35]. Thus, the presence of canonical Babesia/Theileria pRAP-1 genes has yet to be reported in B. microti. We hypothesized that, like Babesia and Theileria parasites, the genome of B. microti also includes genes encoding for pRAP-1 or pRAP-1-like proteins. Furthermore, because of the relatively distant phylogenetic relationship of $B$. microt $i$ with piroplasmid parasites such as Babesia s.s. and Theileria s.s. [1], we propose that the pRAP-1-like proteins encoded by $B$. microti may have diverged dramatically from the pRAP- 1 molecules expressed in other piroplasmids, resulting in a low non-significant sequence identity, but conservation of important structural features. Indeed, neither a common BLASTp nor a Pfam search resulted in hit or domain report, respectively. Therefore, we carried out alternative search strategies on the B. microti genome based on the previously detected conserved synteny in the genome regions of piroplasmid parasites where the prap- 1 loci are encoded and found two head-to-tail oriented linked genes, BMR1_03g00947 and BMR1_03g00960, encoding for proteins with structural characteristics that are compatible with the pRAP-1 molecules. Although the database searches did not result in hits, synteny analysis and the presence of highly conserved amino acid residues of structural importance organized as the Cys-rich domains of the pRAP-1s proteins strongly suggest that the presented two genes encode for pRAP-1 homologs in B. microti. Since these putative B. microti pRAP-1 proteins lack significant sequence identity with pRAP-1 domains of other pRAP-1s, we designated them pRAP-1-like proteins. For the aforementioned reasons, B. microti pRAP-1-like proteins have previously remained unnoticed, though these proteins have been identified and shown to be expressed in B. microti merozoites [35,36].

\section{Results}

\subsection{Two Tandemly Arranged RAP-1 Syntenic Genes of B. microti Encode Proteins Containing} Non-Canonical Piroplasmid RAP-1 Cys-Rich Domains

The piroplasmid RAP-1 proteins contain a characteristic Cys-rich domain, signal peptide, and other short conserved sequence motifs. The salient features of some typical pRAP-1 and RRA representatives of this family are schematized in Figure S1. In this study, we first searched the predicted proteome of the B. microti R1 strain for the identification of proteins containing pRAP-1 Cys motifs using Delta-Blast analysis against a query of the B. bigemina RAP-1c Cys-rich domain (CLGSKDEHHCASQIAAYVARCKE), also typical for the pRAP-1s of B. bovis (Figure 1). This search revealed a hit with the hypothetical protein encoded by gene BMR1_03g00960, here referred to as Bm960 (Figure 1). This finding prompted us to investigate the corresponding gene locus for the presence of other rap-1 related genes and for synteny with B. bovis, B. bigemina and T. equi rap-1 loci. Sequence analysis revealed that the BMR1_03g00947 gene, reffered to as BmIPA48 (Figure S1), located immediately next to Bm960, and separated by an 800-bp intergenic region, encodes for a protein also containing a similar RAP-1-like Cys-rich region, including a key conserved Tyr residue in its amino terminal (Figure 1, Figure 2B,C and Figure S2). 

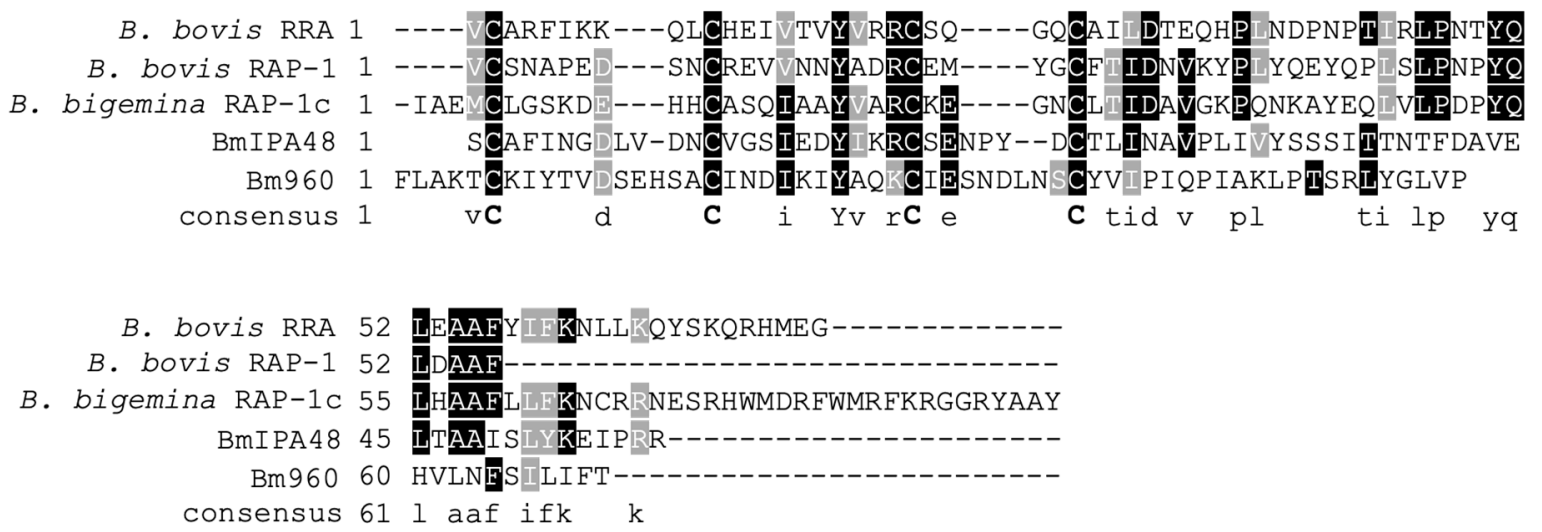

Figure 1. Representative figure of the comparisons performed with the pRAP-1 Cys-rich motif among babesial rRAP-1 proteins and the newly identified B. microti putative pRAP-1. The comparisons include the Cys-rich regions of $B$. bovis RRA, B. bovis RAP-1, B. bigemina RAP-1c, and the B. microti RAP-1- like proteins BmIPA48 and Bm960.

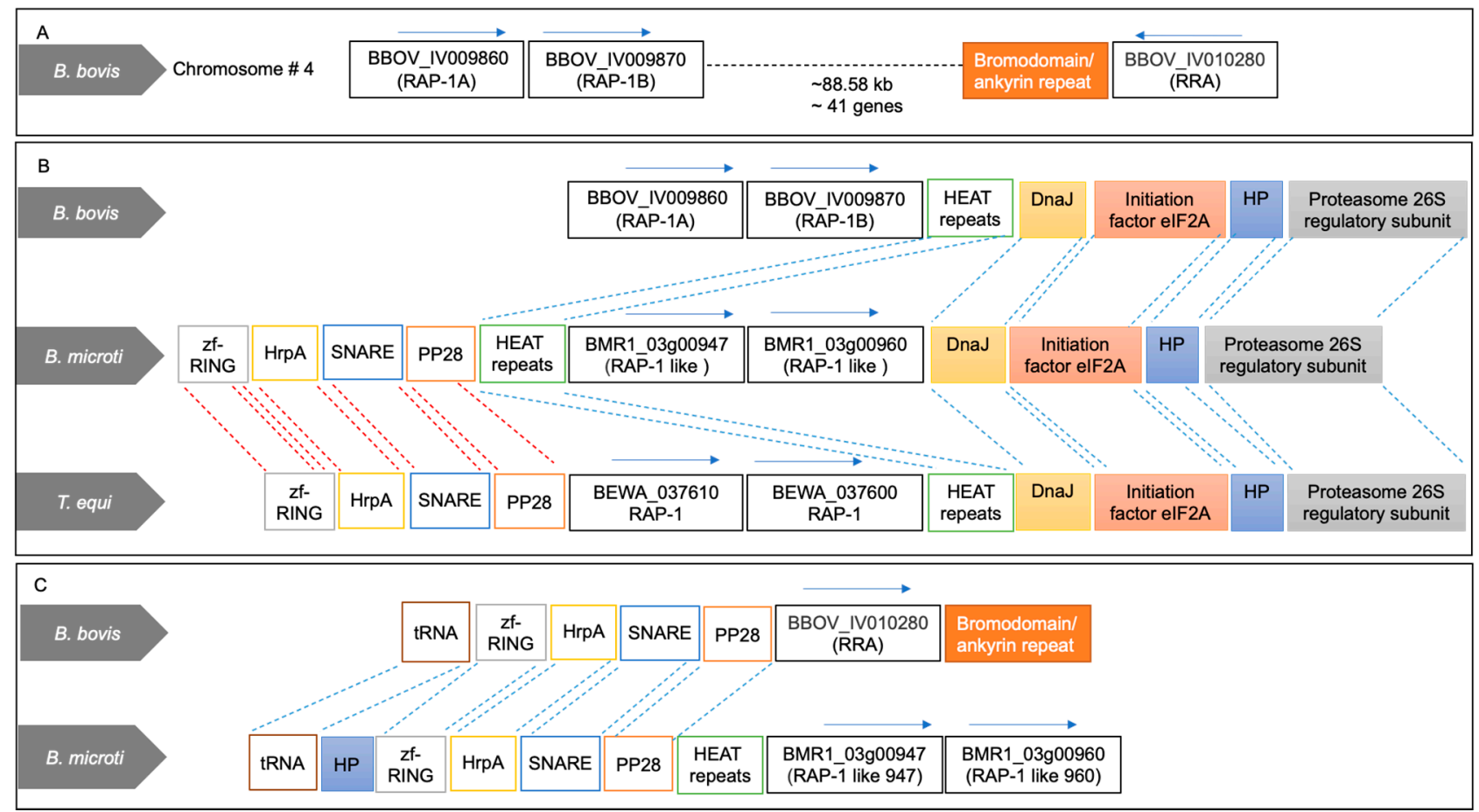

Figure 2. Synteny map of the rap-1 locus of T. equi, putative rap-1 B. microti, and typical s.s. B. bovis. (A) Structure of the prap-1 and rra genes localized in the chromosome 4 of B. bovis. (B) Conserved synteny among the rap-1 loci of B. bovis and T. equi and the BMR1_03g00960 (BmIPA48) and BMR1_03g00947 (Bm960) genes of B. microti, that encode for proteins containing the typical Cys-rich region of the pRAP-1 proteins. (C) Conserved synteny among the B. bovis rra and the B. microti BMR1_03g00960 and BMR1_03g00947 genes.

As shown in Figure 2A, the chromosome 4 of B. bovis contains two identical head-totail arranged prap-1 genes, and a single gene encoding for the RRA protein. These two loci are separated by a $88.5 \mathrm{~kb}$ intervening region containing 41 genes. A comparison between the rap- 1 loci of $B$. bovis and T. equi with the B. microti locus containing BmIPA48 and Bm960 genes is shown in Figure 2B. This illustration shows full synteny in the $5^{\prime}$ and $3^{\prime}$ ends of the B. microti BmIPA48 and Bm960 gene locus and the prap-1 locus of T. equi. In Figure $2 C$ we illustrate partial synteny of the $3^{\prime}$ end of the B. microti genes and the rra locus of $B$. bovis. Besides the presence of the unique Cys-rich regions, there was no significant sequence similarity among the putative pRAP-1 proteins encoded by the BmIPA48 and Bm960 genes (Figure S2). However, the alignment shows conserved Cys, Tyr, 
and other typical residues of the pRAP-1 proteins in the NT-region of the molecules, as well as other short amino acid motifs (Figure S2). The protein encoded by gene BMR1_BmIPA48 also contains a series of tandem repeats in its C-terminal region, a feature that is shared with the $B$. bovis RAP-1 proteins (Figure 3 and Figure S3). Strikingly, sequence analysis of the non-coding regions immediately upstream of genes BmIPA48 and Bm960 revealed conservation of a 300-bp sequence (Figure 3 and Figure S4), suggesting that expression of these two proteins might be coordinated, despite their non-relatedness in sequence. In addtion, secondary structure sequence analysis performed in silico using TMpred suggests that BmIPA48 contains a signal peptide (aa 4-24) and a putative transmembrane (TM) region (aa 164-186) (Figure 4). Since no TM domains were previously reported in this protein, the prediction was confirmed using the alternative algorithm Phobius, which also showed the presence of a TM domain in the same region (Figure S6). Bm960 protein also contains a predicted signal peptide, two TM domains, and lack a predicted GPI anchor attachment site (Figure 4). Collectively, these features are fully consistent with expression on the surface of the parasite, as previously predicted [35].

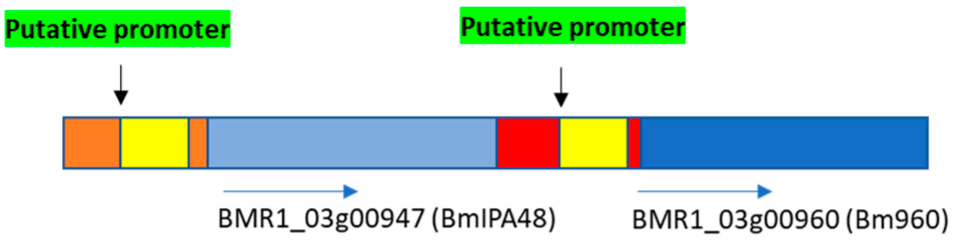

$300 \mathrm{bp}$ non-coding region of homology among the putative $B$. microti pRAP-1 like genes

Non coding region up stream BMR1_03g00947 gene

Non coding region up stream BMR1_03g00960 gene

ORF BMR1_03g00947 (BmIPA48)

ORF BMR1_03g00960 (Bm960)

Figure 3. Schematic representation of the locus encoding for the B. microti RAP-1 putative proteins BmIPA48 and Bm960. A $\sim 300$ bp region upstream the two ORFs is repeated (yellow boxes).

BmIPA48

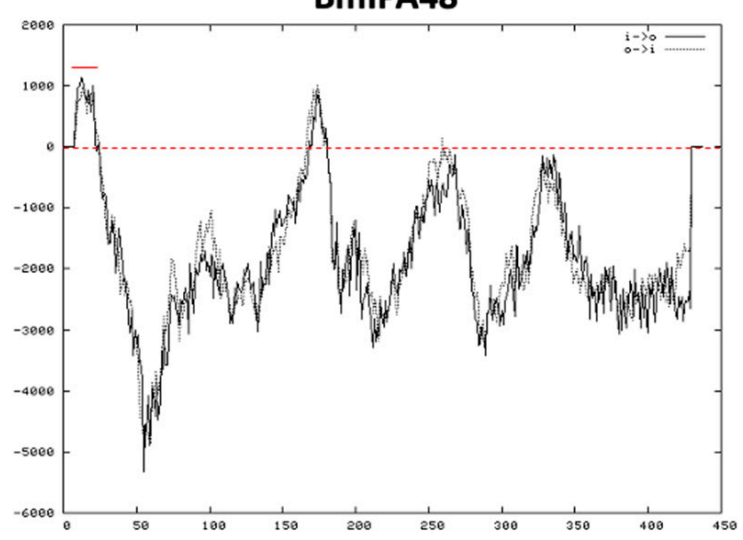

Bm960

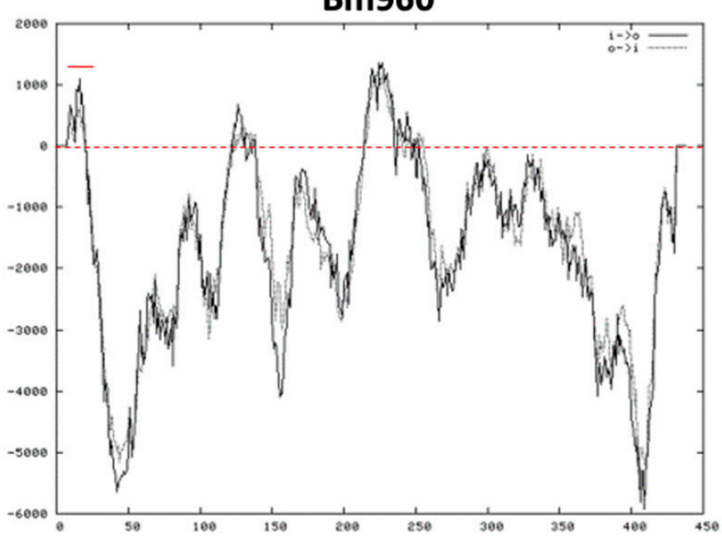

Figure 4. Predicted secondary structure of the pRAP-1-like proteins BmIPA48 and Bm960 using the Program TMpred. Predicted location of signal peptide (SP) is marked with a red bar. A dashed red line marks the boundary between predicted hydrophilic and hydrophobic transmembrane regions of the proteins.

\subsection{Significance of Synteny Relationships among rap-1 and rra Genes of Babesia and Theileria}

After identifying BmIPA48 and Bm960 as two B. microti encoded proteins containing non-canonical piroplasmid RAP-1 Cys-rich domains, we perfomed synteny analysis of these genes. Results showed a remarkable synteny conservation of the rap-1 locus in 
piroplasmids (Figure 2). The BmIPA48 and Bm960 locus is in close vicinity with 3 genes that are also in the neighborhood of the rap-1 genes in B. bovis and Theileria spp. (Figure 2). Moreover, one of these neighboring genes, encoding for the platelet-derived GF associated protein, is also associated with the locus of the rra gene of $B$. bovis. The schematic representation of the rap-1 loci of B. microti, Theileria and Babesia s.s. in Figure 2 suggests the occurrence of a mechanism of genomic rearrangement in a chromosome of an ancestral Babesia organism that resulted in the insertion of an intervening region $(\sim 88 \mathrm{~kb})$ encoding 41 genes in the case of B. bovis (Figure 2A).

\subsection{Phylogeny of Piroplasmid RAP-1 Proteins Recapitulates Piroplasmid Phylogeny}

Next, we inferred on the phylogenetic relationship between amino acid sequences of pRAP-1-like BmIPA48 and Bm960 (Clade I, B. microti-group: B. microti RI) with that of pRAP-1 proteins encoded in available reference genomes of piroplasmid species belonging to Clade II (Western clade: B. duncani WA), Clade III (Cytauxzoon: C. felis Winnie), Clade IV (Equus group: T. equi WA1), Clade V (Theileria s.s: T. annulata Ankara C9, T. parva Muguga, and T. orientalis Shintoku), and Clade VI (Babesia s.s.: B. bovis T2Bo, B. ovata Miyake, B. bigemina Bond, Babesia sp. Xinjiang) (Clades as defined by Schnittger et al. 2012 [1], Jalovecka et al. 2019 [3]) (Figure 5). Based on the assumption that B. microti is distantly related to other piroplasmid species, the tree was rooted using B. microti RI RAP-1-like BmIPA48 as an outgroup. As can be seen in Figure 5, the constructed pRAP-1 protein tree recapitulates phylogenetic lineages of piroplasmids as previously reported [1] However, Bm960 places with a low bootstrap (bs: 34) as sister taxon to remaining Babesia s.s. pRAP-1 proteins due to its low sequence identity with other pRAP-1 proteins.

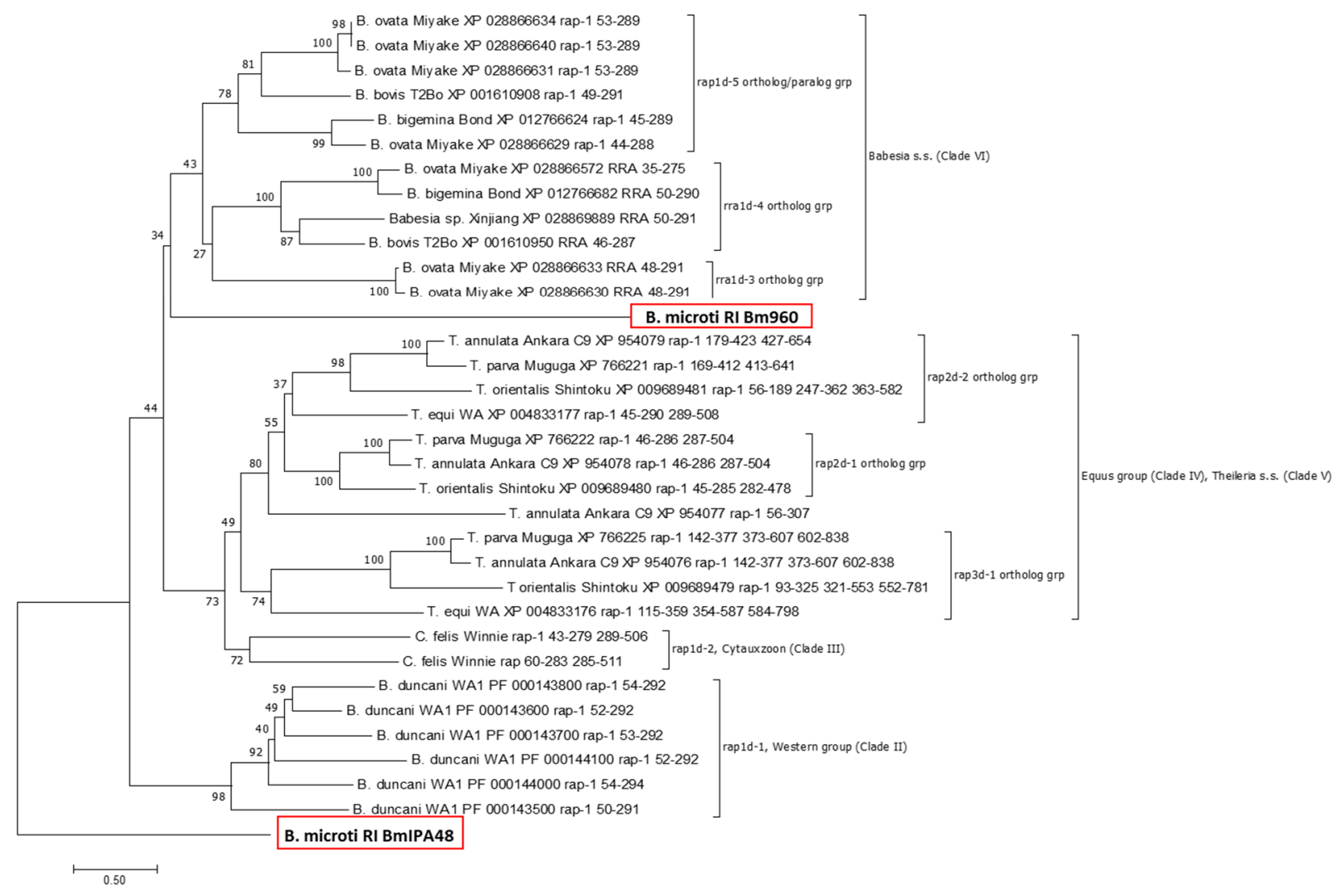

Figure 5. Phylogenetic neighbor joining tree inferred using amino acid sequences of pRAP-1 from the reference genomes of s.s. Babesia (Clade VI), s.s. Theileria (Clade V), T. equi (Clade IV), C. felis (Clade III), and B. duncani (Clade II) and the B. microti RAP-1 proteins BmIPA48 and Bm960 (bold fonts, red boxes). Bootstrap values of 1000 replicates are shown next to the branches. BmIPA48 is used as outgroup. The scale gives the evolutionary distance used to construct the tree. 
Because of the expansion in the number of pRAP-1 domains in Theileria and Cytauxzoon, here we propose a new nomenclature for this gene family, which is based on the number of pRAP-1 domains in encoded proteins and shown in Figures 3 and 5. Thus, rap1d, rap $2 d$, and rap3d genes encode for pRAP-1 proteins that comprise of a single (as seen in B. microti, Clade I; B. duncani, Clade V; and Babesia s.s., Clade VI), a tandemly repeated (as seen in Cytauxzoon, Clade III; T. equi, Clade IV, and Theileria s.s. Clade V), or tandemly triplicated pRAP-1 domains (T. equi, Clade IV, and Theileria s.s. Clade V), respectively (Table 1). Furthermore, an additional number refers to the placement into different orthologous groups within each piroplasmid phylogenetic lineage (Figure 5).

Table 1. Correlation of rap domain architecture and number of rap-1 paralogs with phylogenetic classification of piroplasmids.

\begin{tabular}{|c|c|c|c|c|}
\hline $\begin{array}{l}\text { Species } \\
\text { (Reference } \\
\text { Genome) }\end{array}$ & $\begin{array}{c}\text { Clade } \\
\text { (Sensu } \\
\text { Schnittger et al. } \\
\text { 2012) }\end{array}$ & rap-1 Domain Architectures & $\begin{array}{c}\text { Number of } \\
\text { rap-1 } \\
\text { Paralogs }\end{array}$ & $\begin{array}{l}\text { Nomenclature } \\
\text { (Proposed) }\end{array}$ \\
\hline B. microti & $\begin{array}{l}\mathrm{I}(B . \\
\text { microti-group })\end{array}$ & $={ }_{\text {RAP-1 }}$ & $2 \times$ & rap1d-like \\
\hline B. duncani & II (Western group & $=\mathrm{RAP}=\mathrm{I}$ & $6 \times$ & rap1d-1 \\
\hline C. felis & III (Cytauxzoon) & RAP=1 $\quad$ RAP $=1$ & $2 \times$ & rap1d-2 \\
\hline T. equi & IV (Equus group) & RAP=1 & $\begin{array}{l}1 \times \\
1 \times\end{array}$ & $\begin{array}{l}\operatorname{rap} 2 d-1 \\
\operatorname{rap} 3 d-1\end{array}$ \\
\hline $\begin{array}{l}\text { T. annulata } \\
\text { T. parva } \\
\text { T. orientalis }\end{array}$ & V (Theileria s.s.) & RAPII & $\begin{array}{c}\text { Ta: } 1 \times \\
\text { Tp: } 1 \times, \text { To: } 0 \\
\text { Ta: } 2 \times, \text { Tp: } 2 \times, \text { To: } 2 \times \\
\text { Ta: } 1 \times \\
\text { Tp: } 1 \times, \text { To: } 2 \times\end{array}$ & $\begin{array}{l}\operatorname{rap} 2 d-2 \\
\operatorname{rap} 2 d-1 \\
\operatorname{rap} 3 d-1\end{array}$ \\
\hline $\begin{array}{l}\text { B. bovis } \\
\text { B. bigemina } \\
\text { B. ovata } \\
\text { Babesia sp. } \\
\text { Xinjiang }\end{array}$ & VI (Babesia s.s.) & $\mathrm{R}+\mathrm{P}=1$ & $\begin{array}{l}3 \times \\
2 \times \\
8 \times \\
1 \times\end{array}$ & $\begin{array}{l}\text { rap1d-3 } \\
\text { rap1d-4 } \\
\text { rap1d-5 }\end{array}$ \\
\hline
\end{tabular}

Interestingly, two orthologous groups of Babesia s.s. (rap1d-3 and rap1d-4) correspond with chromosomal rearrangements that have resulted in the generation of RRA proteins, which, although their pRAP-1 domain is complete, are shortened at their C-terminal end and are only found in Babesia s.s. (Figure 1). As shown in Figure 2, Babesia parasites contain two or more copies of pRAP- 1 and a single additional RRA located $\sim 40-80 \mathrm{~kb}$ from the pRAP-1 locus, separated by the insertion of an intervening sequence (Figure 2A). Results show that this is not the case for Theileria parasites, which did not undergo the splitting of the rap-1 locus due to chromosome rearrangements and thus, lack rra genes (Figure 2A).

\subsection{BmIPA48 and Bm960 Are Immunogenic during Infection in Humans}

A previous study identified BmIPA48 and Bm960 proteins as possible biomarkers of acute infection by using a combination of nanoparticle harvesting technology and mass spectrometry on blood derived from B. microti infected hamsters [37]. Even though the antigenicity of Bm960 was not investigated in detail, the protein was not recognized by global antibody screening in rodent models. Bm960 was found to be highly polymorphic among strains [35], and to be present in the plasma of infected hamsters [36], confirming that it is a component of the secretome of the parasite. So far, the immunogenicity of BmIPA48 and Bm960 proteins has remained unknown in B. microti-infected humans. We 
then investigated whether sera from B. microti infected humans contain antibodies that recognize these two proteins. To this end, we expressed and purified recombinant HIStagged truncated forms of BmIPA48 and Bm960 proteins. The recombinant proteins were analyzed in ELISA and immunoblot using previously characterized sera from B. microtiinfected humans (Figure 6). Antibodies from four B. microti-infected individuals recognized BmIPA48 and Bm960 in ELISA. Immunoblot analysis showed that antibodies from infected humans reacted with a product of expected size of BmIPA48 and Bm960 recombinant proteins, as recognized by control anti-HIS monoclonal antibody (Figure 6).

A

\section{BmIPA48}

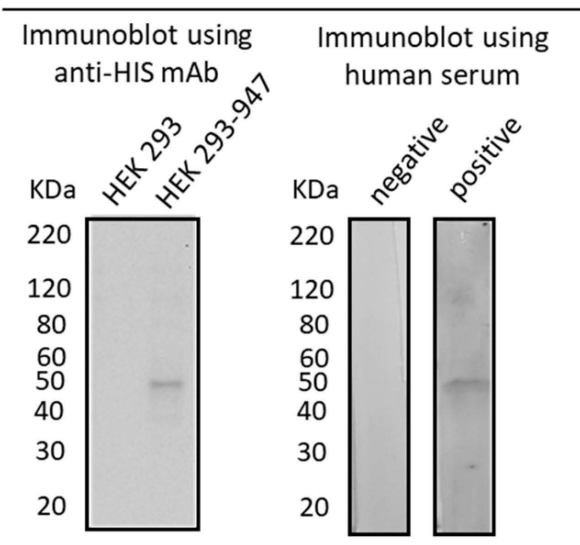

B

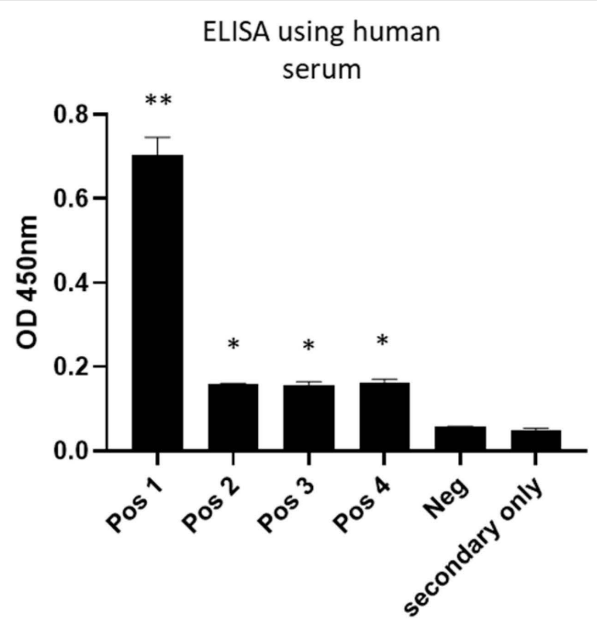

\section{Bm960}

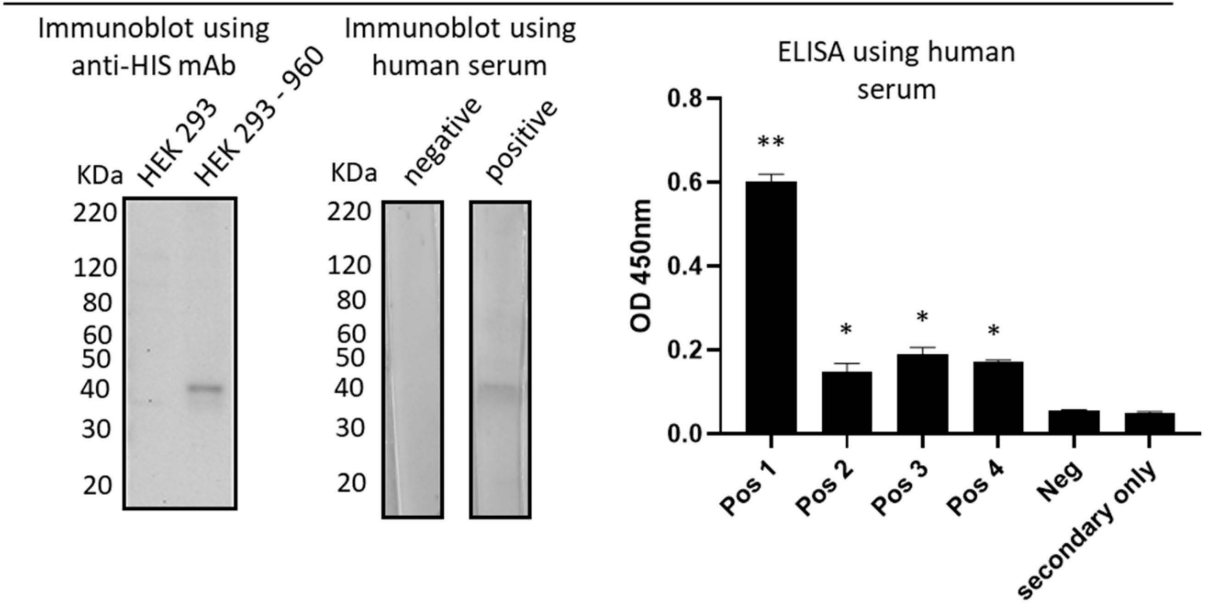

Figure 6. Immunogenicity of BmIPA48 and Bm960 in B. microti-infected humans. Expression of the recombinant BmIPA48 and Bm960 containing a HIS-tag in the immunoblots was demonstrated using an anti-HIS monoclonal antibody (panels (A,B), respectively). A control lysate of cells not expressing the recombinant protein was included as a negative control (HEK 293). Immunoblots were incubated with human B. microti positive and negative sera. ELISAs were performed with four positive (Pos 1, Pos 2, Pos 3, and Pos4) and one negative (Neg) human serum samples were tested. A control sample incubated only with secondary anti-human IgG serum (secondary only) was also included in the ELISA analysis. ${ }^{* *} p<0.001 .{ }^{*} p<0.01$.

\section{Discussion}

In this study we identified two pRAP-1 in B. microti, named BmIPA48 and Bm960. Previous work indicated that BmIPA48 and Bm960 are highly expressed by B. microti merozoites and present in the parasite secretome [35]. The BMR1_03g00947 protein was 
previously identified erroneously as an orthologue of the P. falciparum gene PF3D7_1324300, and given the designation of BmIPA48, which is kept in the present study to avoid confusion $[35,36]$. However, alignment of PF3D7_1324300 and BmIPA48 reveals that their similarity is limited mainly to the glycine residues located in the tandem repeat regions of the two proteins (Figure S5). The tandem repeat region in PF3D7_1324300 is not panconserved among Plasmodium proteins, suggesting that it might lack functional or structural relevance, but instead, it may work as a decoy for the immune system of the host. This observation also suggests that the repeat segment may be a result of convergent evolution, and thus BmIPA48 might not be a true orthologue of PF3D7_1324300. Also, BmIPA48 contains non-synonymous polymorphisms, including a variable microsatellite region, that is highly antigenic and secreted, as part of tubes of vesicles during infection in mice $[14,35]$. In addition, electron microscopy analysis demonstrated that BmIPA48 is localized inside lipid-rich vesicles, which is consistent with their exclusive association with a membrane fraction. Also, IFA shows association of BmIPA48 with the cytoplasm of infected erythrocytes [37]. The presence of previously unnoticed TM domains in BmIPA48 is compatible with the association and export of this protein via lipid-rich vesicles to the cytoplasm of host erythrocytes and eventually to the outside of the host cell, as previously reported [14].

Considering that random gene location associations among four gene loci are highly unlikely in genomes larger than $8 \mathrm{Mb}$ as those of Babesia and Theileria parasites, the data strongly suggest that the BmIPA48 and Bm960 genes are positional equivalents of the Babesia-Theileria rap-1 genes. The biological significance of conserved gene synteny remains undefined. However, co-localization of genes may be important in epigenetic mechanisms and may influence the topology of the chromatin, which in turn can heavily influence coordinated gene expression and gene evolution. It is possible that the presence of syntenic genes results in the advantages of sharing regulatory mechanisms [38]. Sequence analysis of the non-coding regions immediately upstream of BmIPA48 and Bm960 showed conservation of a 300-bp sequence, suggesting a potential coordinated expression of these genes. Notably, a similar feature was found in other Babesia tandemly arranged and closely related or identical gene pairs or triplets, such as the B. bovis rap-1s, $m s a-2 s$, and $e f-1 \alpha$, that share common $5^{\prime}$ untranslated regions [15,39-41].

A remarkable synteny conservation of the rap-1 locus in piroplasmids is shown by the data in our study (Figure 2). In addition, the insertion of an intervening region may have resulted in the splitting of the original rap-1 locus, favoring independent gene evolution of the two identical copies of rap-1 and rra genes [15,26,42]. A similar gene organization is found in B. bigemina with a rra gene separated by a similar large intervening region from a highly diversified and complex rap-1 locus [17]. Interestingly, the intervening region between rra and rap-1 in Babesia parasites is located $\sim 100 \mathrm{~kb}$ upstream in the same chromosome in the B. microti, as well as in the T. equi genomes. However, all the rap-1 genes are located together in a single cluster in this group of organisms, which also lack rra genes. Altogether, comparative analysis of the locus encoding B. microti BmIPA48 and Bm960 proteins with the loci of Babesia and Theileria rap-1 genes provides interesting insights on the synteny and the evolution of the genome of these parasites.

Results from the phylogenetic analysis supports the notion that Bm960 cannot be defined as PRAP-1 based on sequence identity, but only due to structural conservations and synteny. Importantly, it can also be concluded from the phylogenetic tree that pRAP1 is a relatively complex highly polymorphic protein family that underwent multiple duplications into large gene families of paralogs, tandem duplications and triplications of the pRAP-1 cys-rich domain, and a substantial nucleotide diversification, resulting in the existence of multiple highly polymorphic pRAP-1 domains. Thus, this protein family displays a considerable complexity, typically observed for molecules that play a pivotal functional role in the parasite-host interface, such as adhesion, attachment, and invasion, or the interaction with the host immune defense [43]. We hypothesize that the generation of diversification of $\mathrm{pRAP}-1$ proteins is driven by a strong positive selection to optimize adhesion and attachment to their different hosts, as is required for the evolution 
of parasite host-specificity. The different copy number of pRAP-1 domains in a single protein may represent an adaptation strategy to different hosts and life cycles, enabling the parasites to invade different host species and cells. C. felis has two tandemly arranged pRAP-1 proteins containing canonical domains, while most Theileria has pRAP-1 proteins with tandemly duplicated or triplicated pRAP-1 domains. Both the C. felis and Theileria pRAP-1 domains contain 4 conserved Cys residues and a single conserved Tyr residue, as originally described in Babesia $[15,17,26]$. Considering that certain pRAP- 1 features correspond with the phylogenetic classification of piroplasmid species, this finding may be exploited for the development of specific diagnostic tests. Furthermore, pRAP-1 proteins with a duplicated and/or triplicated domain architecture specify the piroplasmid lineages Cytauxzoon, Theileria equi, and Theileria s.s. and contrast with those that encode exclusively single-domain pRAP-1s, such as Babesia s.s. and Babesia s.l. [1].

B. microti contains two prap-1-like genes located as a single cluster in the region of the genome where s.s. Babesia and Theileria organisms contain their prap-1 genes. These two genes have a fully conserved synteny and identical flanking genes as Theileria parasites, as shown in Figure 2A. This implies that the aforementioned genome rearrangements resulted in an independent evolution of RRA encoding genes, which likely occurred after Babesia organisms emerged as separate species from a common Babesia and Theileria ancestor. This notion is further supported by the observation that all proteins segregating into the rap $1 d-3$ and the rap $1 d-4$ orthologous groups represent RRA proteins since, although they contain a complete pRAP-1 domain, are shortened at the C-terminal end (Figure 1). This strongly suggests that the ancient RRA protein has lost its $\mathrm{C}$-terminal partly due to chromosomal rearrangement and places this event before the diversification of the RRA proteins.

Considering that the antigenicity of BmIPA48 and Bm960 was not previously investigated [35-37,39], here we examined sera from B. microti-infected humans for the presence of antibodies against these proteins. Collectively, results of ELISA and immunoblot indicate that BmIPA48 and Bm960 are immunogenic during infection in humans, and thus should be considered for further testing as possible candidates for serological diagnosis of human babesiosis caused by B. microti. In addition, because of their previously established high degree of expression, surface localization, conservation, and immunogenicity, BmIPA48 and $\mathrm{Bm} 960$ proteins might also be promising candidates for the development of vaccines that may prevent human babesiosis.

\section{Materials and Methods}

\subsection{Expression of Recombinant B. microti pRAP-1 like Proteins}

The predicted proteins encoded by B. microti BMR1_03g00947 and BMR1_03g00960 (GenBank accession numbers: XP_021338473 and XP_021338474, respectively), here referred to as BmIPA48 and Bm960, respectively, were analyzed by the Kyte-Doolittle scale for the presence of hydrophobic regions as previously described [44]. As a result, $105 \mathrm{nt}$ and 84 nt-long fragments located at the 5' end of BMR1_03g00947 and BMR1_03g00960, correspondingly, encoding hydrophobic peptide segments, were excluded from the cloning and protein expression experiments described in this work. The resulting nucleotide sequences were codon-optimized for mammalian cell expression, synthesized by GenArt Gene Synthesis (Thermo Fisher Scientific, Waltham, MA, USA) and cloned into pcDNA3.4. Recombinant plasmids containing either truncated BMR1_03g00947 (pcDNA3.4/947) or truncated BMR1_03g00960 (pcDNA3.4/960) were fully sequenced to confirm the presence of the target genes in frame with the cytomegalovirus promoter (data not shown). Subsequently, HEK 293 cells were transiently transfected with either pcDNA3.4/947 or pcDNA3.4/960 using polyethylenimine, as described elsewhere [45]. Expression of the recombinant truncated proteins (BmIPA48tr and Bm960tr) was confirmed by immunoblot using the anti-6xHis monoclonal antibody (clone AD1.1.10) (Bio-Rad, Hercules, CA, USA). Recombinant BmIPA48tr and Bm960tr were purified using the HisPur ${ }^{\mathrm{TM}}$ Cobalt Purification Kit following the manufacturer's protocol (Thermo Fisher Scientific). After purification, the 
recombinant proteins were dialyzed using the Slide-A-Lyzer ${ }^{\mathrm{TM}}$ Dialysis cassettes (Thermo Fisher Scientific) and stored at $-80^{\circ} \mathrm{C}$ until use for ELISA and immunoblot.

\subsection{Human Serum Samples}

Unidentified human patient serum samples were submitted to Fuller Laboratories from Labcorp, NC for anti-B. microti IgG determination. No clinical data were provided for any of the specimens.

\subsection{ELISA Procedure}

Antigen dilution was performed by mixing $8 \mu \mathrm{L}$ of recombinant BmIPA48 antigen (approx. 0.5 $\mu \mathrm{g} / \mu \mathrm{L}$ ) in $500 \mu \mathrm{L}$ PBS buffer followed by two-fold dilutions 1:2, 1:4 and 1:8. For Bm960, $4 \mu \mathrm{L}$ of the recombinant antigen (approx. $1 \mu \mathrm{g} / \mu \mathrm{L}$ ) was mixed in $500 \mu \mathrm{L}$ PBS buffer, and then diluted two-fold 1:2, 1:4 and 1:8. Two neighboring strips of the ELISA plate were coated with $100 \mu \mathrm{L} /$ well of 1:4 and 1:8 antigen dilutions. The antigen-coated plates were incubated at room temperature $\left(23-25^{\circ} \mathrm{C}\right)$ overnight, then back coated by adding $100 \mu \mathrm{L} /$ well WellChampion (Microwell Plate Blocker/Stabilizer, Kementec, Copenhagen, Denmark) to each well for 5-10 min. Plates were then decanted and allowed to dry overnight in a dark low-humidity room before use. Negative serum control was obtained from a non-reactive unidentified human patient, which tested negative in confirmatory IFA analysis. Positive controls $(n=4)$ corresponded to anti-B. microti IgG and IgM reactive unidentified human sera with IFA endpoint titers $>$ 1:1024 (cat. BMG-120, Fuller Laboratories, Fullerton, CA, USA). IFA testing utilized both hamster in vivo and human type $\mathrm{O}$ in vitro antigen (US 10,087,412 B2 patent). All sera were diluted 1:100 in sample diluent (PBS/ $2 \mathrm{mg} / \mathrm{mL}$ bovine serum albumin/0.1\% Tween-20). One hundred $\mu \mathrm{L}$ aliquots of diluted sera were added to ELISA plate microwells. Two rows of microwells were filled with sample diluent and were used for secondary antibody controls. Plates were covered to minimize evaporation and incubated for $60 \mathrm{~min}$ at room temperature. Then, plates were washed four times with wash buffer (PBS/0.1\% Tween-20). One hundred $\mu \mathrm{L}$ of a working dilution of anti-human IgG ( $\gamma$-chain-specific)-horseradish peroxidase (HRP) conjugate (SFG-1X, Fuller Labs) were added to each well, and the plate was covered and incubated for $30 \mathrm{~min}$ at RT in the dark. Microwells were washed as above and $100 \mu \mathrm{L} \mathrm{TMB}$ substrate was added to each well. Reactions were allowed to proceed for exactly $10 \mathrm{~min}$ in the dark and interrupted by adding $100 \mu \mathrm{L}$ Stop solution ( $0.36 \mathrm{~N}$ sulfuric acid). Absorbance at $450 \mathrm{~nm}$ was read in a microplate reader (MultiSkan MCC/340, Titertek, Pforzheim, Germany). Absorbance values of $B$. microti positive and negative sera were compared by Student's $t$-test using Prism version 6 (GraphPad Software, San Diego, CA, USA).

\subsection{Immunoblot Analysis}

For human serum analysis, aliquots $(45 \mu \mathrm{L})$ of recombinant BmIPA48 and Bm960 antigens were separated using 10\% Mini-PROTEAN ${ }^{\circledR}$ TGX $^{\mathrm{TM}}$ Precast Protein Gels (BioRad, Cat \#4561034) and transferred to PVDF membranes. Membranes were blocked with $5 \%$ milk, cut into strips, and individually incubated overnight at $4{ }^{\circ} \mathrm{C}$ with $\mathrm{B}$. microtipositive or negative patient sera, in a 1:250 dilution. Membranes were then washed with PBS/0.1\% Tween-20 and incubated for $1 \mathrm{~h}$ with HRP-conjugated secondary antibody (1:10,000 dilution). Following additional washings, membranes were incubated with Opti4CN substrate diluted in 1-part Opti-4CN diluent and 9 parts distilled water (Bio-Rad, Cat\# 1708235) for 5-30 min until the desired the signal was obtained.

\subsection{Bioinformatic Analysis}

Secondary sequence analysis was performed using TMpred Server (vital-it.ch, accessed on 1 August 2021) and Phobius (phobius.sbc.su.se, accessed on 1 August 2021). Prediction of GPI anchor signals was carried out using PredGPI (gpcr.biocomp.unibo.it/ predgpi/, accessed on 1 August 2021). Synteny studies were carried out by exploring the Piroplasma DB database (piroplasmadb.org/piro/app, accessed on 1 August 2021). 


\subsection{Phylogenetic Analysis}

The amino acid sequence of B. bovis T2Bo RAP-1 (XP_001610908) was used in a BLASTp search, adjusting parameter settings to piroplasmid sequences (taxid:5863) and reference proteins to identify homologs in completely sequenced genomes of piroplasmid species. The genomes analyzed included B. bigemina strain Bond [46], B. bovis strain T2Bo [47], B. ovata strain Miyake [48], B. microti strain RI [35], C. felis strain Winnie [49], T. annulata strain Ankara [50], T. equi strain WA [51], T. orientalis strain Shintoku [52], and T. parva strain Muguga [53]. In addition, RAP-1 sequences of $B$. duncani were retrieved by courtesy from yet public unavailable genomes (B. duncani strain WA1: Choukri Ben Mamoun, Yale School of Medicine, New Haven, CT, USA). Finally, BmIPA48 and Bm960 were identified by delta Blast using a RAP-1 region containing 4 conserved Cys, as described before.

Altogether 34 amino acid sequences were aligned by Muscle (www.ebi.ac.uk/Tools/ $\mathrm{msa} /$ muscle / , accessed on 30 July 2021). In order to estimate evolutionary distances, the $\mathrm{JTT}+\mathrm{G}(\mathrm{G}=5.93)$ was determined as best model by BIC criteria and applied [54]. After eliminating all positions with gaps and missing data, the remaining 212 positions were used for estimation of a neighbor joining tree [55]. The phylogenetic analysis was carried out using MEGA7 [56].

\section{Conclusions}

Findings in this study suggest that rap-1 genes appeared early in the evolution of piroplasmid parasites, implying that expression of prap-1 and prap-1-like genes is required for sustaining the life cycle of these organisms. Two tandemly arranged genes separated by an 800 bp intergenic region that includes a highly conserved putative promoter region are located in a region of the $B$. microti genome with strong synteny to the prap- 1 locus of Babesia and Theileria parasites. The organization of these two prap-1-like B. microti genes is reminiscent of the organization of the prap-1 locus in B. bovis [15]. This feature, together with the presence of a single Cys-rich pRAP-1 motif in the encoded proteins resembles pRAP-1/RRA proteins of Babesia, rather than Theileria, parasites, but with identical synteny to Theileria parasites. The presence of a shared 300-bp region in the putative regulatory DNA regions suggests that the expression of these genes might be co-regulated. Both B. microti proteins contain TM domains and signal peptides, which is consistent with extracellular vesicle localization. Previous work showed that Bm960 is secreted into the sera of infected mice [35] and that BmIPA48 is strongly immunogenic in infected hamsters [14,36]. The gene structure comparison and phylogenetic analysis of the prap-1 locus among distinct piroplasmid parasites allowed valuable insights on the genetic mechanisms involved in the evolution of the members of this piroplasmid-confined gene family. Importantly, this work also confirmed that antibodies in B. microti-infected humans recognized the recombinant forms of both proteins, so their potential as candidates for diagnostic assays and vaccines should be further explored.

Supplementary Materials: The following are available online at https: / www.mdpi.com/article/ 10.3390 / pathogens10111384/s1, Figure S1. Schematic representation of the structural features of RAP-1 and RRA proteins, Figure S2. Amino acid sequence alignment between the BmIPA48 and Bm960 RAP-1 like proteins, Figure S3. Amino acid sequence of the Bm947 protein, Figure S4. Schematic representation of the $300 \mathrm{bp}$ region of homology among the B. microti RAP-1 like genes BMR1_03g00947 (947) and BMR1_03g00960 (960), Figure S5. Amino acid alignment between BmIPA48 $(\mathrm{Bm})$ and PF3D7_1324300 (Pf), and Figure S6. Secondary structure prediction of BmIPA48using the software Phoebius. 
Author Contributions: Conceptualization, R.G.B. and C.E.S.; Data curation, R.G.B. and C.E.S.; Formal analysis, R.G.B., J.T., C.B.M., L.F., R.E.M., M.F.-C., L.S., H.F.A. and C.E.S.; Funding acquisition, R.G.B., C.B.M., L.F., R.E.M., M.F.-C. and C.E.S.; Investigation, R.G.B., J.T., C.B.M., L.F., R.E.M., M.F.C., L.S., H.F.A. and C.E.S.; Methodology, R.G.B., J.T., C.B.M., L.F., M.F.-C., L.S., H.F.A. and C.E.S.; Software, R.G.B., M.F.-C., L.S. and C.E.S.; Validation, R.G.B., J.T., C.B.M., L.F., R.E.M., M.F.-C., L.S., H.F.A. and C.E.S.; Writing-original draft, R.G.B., J.T., M.F.-C., L.S. and C.E.S.; Writing-review \& editing, R.G.B., J.T., C.B.M., L.F., R.E.M., M.F.-C., L.S., H.F.A. and C.E.S. All authors have read and agreed to the published version of the manuscript.

Funding: RB is supported by the USDA National Institute of Food and Agriculture (NIFA) (Award Number: 2020-67015-31809; Proposal Number: 2019-05375, Accession Number: 1022541. Work supported by ARS-USDA CRIS 2090-32000-039-000-D. CBM research is supported by NIH grants AI123321, AI138139, AI152220 and AI136118, the Steven and Alexandra Cohen Foundation and Global Lyme Alliance. The financial support of MFC and LS by INTA (Instituto Nacional de Tecnologia Agropecuaria) projects 2019-PD-E5-I102-001 and 2019-PE-E5-I109-001 is acknowledged. REM is supported by ATCC's Internal Research and Development Program.

Institutional Review Board Statement: Not applicable.

Informed Consent Statement: As mentioned in the Material and Methods section, unidentified human patient serum samples used in this study were submitted to Fuller Laboratories from Labcorp, NC for anti-B. microti IgG determination. No clinical data were provided for any of the specimens.

Data Availability Statement: Not applicable.

Acknowledgments: The authors would like to acknowledge Sezayi Ozubek, Paul Lacy, Jacob Laughery, Manuel Rojas (DVM), and Jinna Navas for productive discussions and technical assistance.

Conflicts of Interest: The authors declare no conflict of interest.

\section{References}

1. Schnittger, L.; Rodriguez, A.E.; Florin-Christensen, M.; Morrison, D.A. Babesia: A world emerging. Infect. Genet. Evol. 2012, 12, 1788-1809. [CrossRef]

2. Jalovecka, M.; Hajdusek, O.; Sojka, D.; Kopacek, P.; Malandrin, L. The Complexity of Piroplasms Life Cycles. Front. Cell. Infect. Microbiol. 2018, 8, 248. [CrossRef] [PubMed]

3. Jalovecka, M.; Sojka, D.; Ascencio, M.; Schnittger, L. Babesia Life Cycle-When Phylogeny Meets Biology. Trends Parasitol. 2019, 35, 356-368. [CrossRef]

4. Yang, Y.; Christie, J.; Köster, L.; Du, A.; Yao, C. Emerging Human Babesiosis with “Ground Zero" in North America. Microorganisms 2021, 9, 440. [CrossRef]

5. Karshima, S.N.; Karshima, M.N.; Ahmed, M.I. Animal reservoirs of zoonotic Babesia species: A global systematic review and meta-analysis of their prevalence, distribution and species diversity. Vet. Parasitol. 2021, 298, 109539. [CrossRef] [PubMed]

6. Lobo, C.A.; Singh, M.; Rodriguez, M. Human babesiosis: Recent advances and future challenges. Curr. Opin. Hematol. 2020, 27, 399-405. [CrossRef] [PubMed]

7. Tang, T.T.M.; Tran, M.-H. Transfusion transmitted babesiosis: A systematic review of reported cases. Transfus. Apher. Sci. 2020, 59, 102843. [CrossRef] [PubMed]

8. Alkishe, A.; Raghavan, R.; Peterson, A. Likely geographic distributional shifts among medically important tick species and tick-associated diseases under climate change in North America: A review. Insects 2021, 12, 225. [CrossRef]

9. Tufts, D.M.; A Diuk-Wasser, M. Vertical Transmission: A vector-independent transmission pathway of Babesia microti in the natural reservoir host. Peromyscus. Leucopus. J. Infect. Dis. 2020, 223, 1787-1795. [CrossRef] [PubMed]

10. White, D.J.; Talarico, J.; Chang, H.-G.; Birkhead, G.S.; Heimberger, T.; Morse, D.L. Human babesiosis in New York State. Arch. Intern. Med. 1998, 158, 2149-2154. [CrossRef]

11. Gubbels, M.-J.; Duraisingh, M.T. Evolution of apicomplexan secretory organelles. Int. J. Parasitol. 2012, 42, 1071-1081. [CrossRef] [PubMed]

12. Robert-Paganin, J.; Xu, X.-P.; Swift, M.F.; Auguin, D.; Robblee, J.P.; Lu, H.; Fagnant, P.M.; Krementsova, E.B.; Trybus, K.M.; Houdusse, A.; et al. The actomyosin interface contains an evolutionary conserved core and an ancillary interface involved in specificity. Nat. Commun. 2021, 12,1-11. [CrossRef]

13. Ben Chaabene, R.; Lentini, G.; Soldati-Favre, D. Biogenesis and discharge of the rhoptries: Key organelles for entry and hijack of host cells by the Apicomplexa. Mol. Microbiol. 2020, 115, 453-465. [CrossRef]

14. Thekkiniath, J.; Kilian, N.; Lawres, L.; A Gewirtz, M.; Graham, M.M.; Liu, X.; Ledizet, M.; Ben Mamoun, C. Evidence for vesicle-mediated antigen export by the human pathogen. Babesia Microti. Life Sci. Alliance. 2019, 2, e201900382. [CrossRef] [PubMed] 
15. Suarez, C.E.; Palmer, G.H.; Hotzel, I.; McElwain, T.F. Structure, sequence, and transcriptional analysis of the Babesia bovis rap-1 multigene locus. Mol. Biochem. Parasitol. 1998, 93, 215-224. [CrossRef] [PubMed]

16. Kappmeyer, L.; Perryman, L.E.; Hines, S.A.; Baszler, T.V.; Katz, J.B.; Hennager, S.G.; Knowles, D.P. Detection of equine antibodies to Babesia caballi by recombinant $B$. caballi rhoptry-associated protein 1 in a competitive-inhibition enzyme-linked immunosorbent assay. J. Clin. Microbiol. 1999, 37, 2285-2290. [CrossRef]

17. Suarez, C.E.; Palmer, G.H.; Florin-Christensen, M.; Hines, S.A.; Hötzel, I.; McElwain, T.F. Organization, transcription, and expression of rhoptry associated protein genes in the Babesia bigemina rap-1 locus. Mol. Biochem. Parasitol. 2003, 127, 101-112. [CrossRef]

18. Zhou, J.; Jia, H.; Nishikawa, Y.; Fujisaki, K.; Xuan, X. Babesia gibsoni rhoptry-associated protein 1 and its potential use as a diagnostic antigen. Vet. Parasitol. 2007, 145, 16-20. [CrossRef] [PubMed]

19. Terkawi, M.A.; Amornthep, A.; Ooka, H.; Aboge, G.; Jia, H.; Goo, Y.-K.; Nelson, B.; Yamagishi, J.; Nishikawa, Y.; Igarashi, I.; et al. Molecular characterizations of three distinct Babesia gibsoni rhoptry-associated protein-1s (RAP-1s). Parasitology 2009, 136, 1147-1160. [CrossRef] [PubMed]

20. Rodriguez, M.; Alhassan, A.; Ord, R.L.; Cursino-Santos, J.R.; Singh, M.; Gray, J.; Lobo, C.A. Identification and characterization of the RouenBd1987 Babesia divergens rhopty-associated protein 1. PLoS ONE 2014, 9, e107727. [CrossRef]

21. Yu, Q.; He, L.; Zhang, W.-J.; Cheng, J.-X.; Hu, J.-F.; Miao, X.-Y.; Huang, Y.; Fan, L.-Z.; Khan, M.K.; Zhou, Y.-Q.; et al. Molecular cloning and characterization of Babesia orientalis rhoptry-associated protein 1. Vet. Parasitol. 2014, 205, 499-505. [CrossRef] [PubMed]

22. Niu, Q.; Bonsergent, C.; Guan, G.; Yin, H.; Malandrin, L. Sequence and organization of the rhoptry-associated-protein-1 (rap-1) locus for the sheep hemoprotozoan Babesia sp. BQ1 Lintan (B. motasi phylogenetic group). Vet. Parasitol. 2013, 198, 24-38. [CrossRef] [PubMed]

23. Niu, Q.; Marchand, J.; Yang, C.; Bonsergent, C.; Guan, G.; Yin, H.; Malandrin, L. Rhoptry-associated protein (rap-1) genes in the sheep pathogen Babesia sp. Xinjiang: Multiple transcribed copies differing by $3^{\prime}$ end repeated sequences. Vet. Parasitol. 2015, 211, 158-169. [CrossRef] [PubMed]

24. Shaw, M.K. Cell invasion by Theileria sporozoites. Trends Parasitol. 2003, 19, 2-6. [CrossRef]

25. Yokoyama, N.; Suthisak, B.; Hirata, H.; Matsuo, T.; Inoue, N.; Sugimoto, C.; Igarashi, I. Cellular localization of Babesia bovis merozoite rhoptry-associated protein 1 and its erythrocyte-binding activity. Infect. Immun. 2002, 70, 5822-5826. [CrossRef] [PubMed]

26. Suarez, C.E.; Laughery, J.M.; Bastos, R.G.; Johnson, W.C.; Norimine, J.; Asenzo, G.; Brown, W.C.; Florin-Christensen, M.; Goff, W.L. A novel neutralization sensitive and subdominant RAP-1-related antigen (RRA) is expressed by Babesia bovis merozoites. Parasitology 2011, 138, 809-818. [CrossRef] [PubMed]

27. Moreno, R.; Pöltl-Frank, F.; Stüber, D.; Matile, H.; Mutz, M.; Weiss, N.A.; Pluschke, G. Rhoptry-associated protein 1-binding monoclonal antibody raised against a heterologous peptide sequence inhibits Plasmodium falciparum growth in vitro. Infect. Immun. 2001, 69, 2558-2568. [CrossRef] [PubMed]

28. Ushe, T.C.; Palmer, G.H.; Sotomayor, L.; Figueroa, J.V.; Buening, G.M.; E Perryman, L.; McElwain, T.F. Antibody response to a Babesia bigemina rhoptry-associated protein 1 surface-exposed and neutralization-sensitive epitope in immune cattle. Infect. Immun. 1994, 62, 5698-5701. [CrossRef]

29. Mosqueda, J.; McElwain, T.F.; Stiller, D.; Palmer, G.H. Babesia bovis Merozoite surface antigen 1 and rhoptry-associated protein 1 are expressed in sporozoites, and specific antibodies inhibit sporozoite attachment to erythrocytes. Infect. Immun. 2002, 70, 1599-1603. [CrossRef]

30. Norimine, J.; Suarez, C.E.; McElwain, T.F.; Florin-Christensen, M.; Brown, W.C. Immunodominant epitopes in Babesia bovis rhoptry-associated protein 1 that elicit memory CD4(+)-T-lymphocyte responses in B. bovis-immune individuals are located in the amino-terminal domain. Infect. Immun. 2002, 70, 2039-2048. [CrossRef] [PubMed]

31. Boonchit, S.; Xuan, X.; Yokoyama, N.; Goff, W.L.; Waghela, S.D.; Wagner, G.; Igarashi, I. Improved enzyme-linked immunosorbent assay using c-terminal truncated recombinant antigens of Babesia bovis rhoptry-associated protein-1 for detection of specific antibodies. J. Clin. Microbiol. 2004, 42, 1601-1604. [CrossRef] [PubMed]

32. Boonchit, S.; Alhassan, A.; Chan, B.; Xuan, X.; Yokoyama, N.; Ooshiro, M.; Goff, W.L.; Waghela, S.D.; Wagner, G.; Igarashi, I. Expression of C-terminal truncated and full-length Babesia bigemina rhoptry-associated protein 1 and their potential use in enzyme-linked immunosorbent assay. Vet. Parasitol. 2006, 137, 28-35. [CrossRef] [PubMed]

33. Suarez, C.E.; Noh, S. Emerging perspectives in the research of bovine babesiosis and anaplasmosis. Vet. Parasitol. 2011, 180, 109-125. [CrossRef] [PubMed]

34. Niu, Q.; Liu, Z.; Yang, J.; Yu, P.; Pan, Y.; Zhai, B.; Luo, J.; Moreau, E.; Guan, G.; Yin, H. Expression analysis and biological characterization of Babesia sp. BQ1 (Lintan) (Babesia motasi-like) rhoptry-associated protein 1 and its potential use in serodiagnosis via ELISA. Parasites Vectors. 2016, 9, 1-14. [CrossRef] [PubMed]

35. Silva, J.C.; Cornillot, E.; McCracken, C.; Usmani-Brown, S.; Dwivedi, A.; Ifeonu, O.O.; Crabtree, J.; Gotia, H.T.; Virji, A.Z.; Reynes, C.; et al. Genome-wide diversity and gene expression profiling of Babesia microti isolates identify polymorphic genes that mediate host-pathogen interactions. Sci. Rep. 2016, 6, 35284. [CrossRef] [PubMed]

36. Magni, R.; Luchini, A.; Liotta, L.; Molestina, R.E. Analysis of the Babesia microti proteome in infected red blood cells by a combination of nanotechnology and mass spectrometry. Int. J. Parasitol. 2018, 49, 139-144. [CrossRef] [PubMed] 
37. Magni, R.; Luchini, A.; Liotta, L.; Molestina, R.E. Proteomic analysis reveals pathogen-derived biomarkers of acute babesiosis in erythrocytes, plasma, and urine of infected hamsters. Parasitol. Res. 2020, 119, 2227-2235. [CrossRef]

38. Moreno-Hagelsieb, G.; Trevino, V.; Perez-Rueda, E.; Smith, T.F.; Collado-Vides, J. Transcription unit conservation in the three domains of life: A perspective from Escherichia coli. Trends Genet. 2001, 17, 175-177. [CrossRef]

39. Florin-Christensen, M.; Suarez, C.E.; Hines, S.A.; Palmer, G.H.; Brown, W.C.; McElwain, T.F. The Babesia bovis merozoite surface antigen 2 locus contains four tandemly arranged and expressed genes encoding immunologically distinct proteins. Infect. Immun. 2002, 70, 3566-3575. [CrossRef]

40. Suarez, C.E.; Norimine, J.; Lacy, P.; McElwain, T.F. Characterization and gene expression of Babesia bovis elongation factor-1 $\alpha$. Int. J. Parasitol. 2006, 36, 965-973. [CrossRef] [PubMed]

41. Silva, M.G.; Knowles, D.P.; Mazuz, M.L.; Cooke, B.M.; Suarez, C.E. Stable transformation of Babesia bigemina and Babesia bovis using a single transfection plasmid. Sci. Rep. 2018, 8, 1-9. [CrossRef]

42. Suarez, C.E.; Palmer, G.H.; Jasmer, D.P.; Hines, S.A.; Perryman, L.E.; McElwain, T.F. Characterization of the gene encoding a 60-kilodalton Babesia bovis merozoite protein with conserved and surface exposed epitopes. Mol. Biochem. Parasitol. 1991, 46, 45-52. [CrossRef]

43. Paing, M.M.; Tolia, N.H. multimeric assembly of host-pathogen adhesion complexes involved in apicomplexan invasion. PLOS Pathog. 2014, 10, e1004120. [CrossRef] [PubMed]

44. Kyte, J.; Doolittle, R.F. A simple method for displaying the hydropathic character of a protein. J. Mol. Biol. 1982, 157, 105-132 [CrossRef]

45. Bastos, R.G.; Franceschi, V.; Tebaldi, G.; Connelley, T.; Morrison, W.I.; Knowles, D.P.; Donofrio, G.; Fry, L.M. Molecular and antigenic properties of mammalian cell-expressed Theileria parva antigen Tp9. Front. Immunol. 2019, 10, 897. [CrossRef] [PubMed]

46. Jackson, A.P.; Otto, T.; Darby, A.; Ramaprasad, A.; Xia, D.; Echaide, I.E.; Farber, M.; Gahlot, S.; Gamble, J.; Gupta, D.; et al The evolutionary dynamics of variant antigen genes in Babesia reveal a history of genomic innovation underlying host-parasite interaction. Nucleic Acids Res. 2014, 42, 7113-7131. [CrossRef] [PubMed]

47. A Brayton, K.; Lau, A.; Herndon, D.R.; Hannick, L.; Kappmeyer, L.; Berens, S.J.; Bidwell, S.L.; Brown, W.C.; Crabtree, J.; Fadrosh, D.; et al. Genome sequence of Babesia bovis and comparative analysis of apicomplexan hemoprotozoa. PLoS Pathog. 2007, 3, e148. [CrossRef] [PubMed]

48. Yamagishi, J.; Asada, M.; Hakimi, H.; Tanaka, T.Q.; Sugimoto, C.; Kawazu, S.-I. Whole-genome assembly of Babesia ovata and comparative genomics between closely related pathogens. BMC Genom. 2017, 18, 1-9. [CrossRef]

49. Tarigo, J.L.; Scholl, E.H.; Bird, D.; Brown, C.C.; Cohn, L.A.; Dean, G.A.; Levy, M.G.; Doolan, D.L.; Trieu, A.; Nordone, S.K.; et al. A novel candidate vaccine for Cytauxzoonosis inferred from comparative apicomplexan genomics. PLoS ONE 2013, 8, e71233. [CrossRef]

50. Pain, A.; Renauld, H.; Berriman, M.; Murphy, L.; Yeats, C.A.; Weir, W.; Kerhornou, A.; Aslett, M.; Bishop, R.; Bouchier, C.; et al. Genome of the host-cell transforming parasite Theileria annulata compared with T. parva. Science 2005, 309, 131-133. [CrossRef] [PubMed]

51. Kappmeyer, L.S.; Thiagarajan, M.; Herndon, D.R.; Ramsay, J.D.; Caler, E.; Djikeng, A.; Gillespie, J.J.; Lau, A.O.; Roalson, E.H.; Silva, J.C.; et al. Comparative genomic analysis and phylogenetic position of Theileria equi. BMC Genom. 2012, 13, 603. [CrossRef] [PubMed]

52. Hayashida, K.; Hara, Y.; Abe, T.; Yamasaki, C.; Toyoda, A.; Kosuge, T.; Suzuki, Y.; Sato, Y.; Kawashima, S.; Katayama, T.; et al. Comparative genome analysis of three eukaryotic parasites with differing abilities to transform leukocytes reveals key mediators of Theileria-induced leukocyte transformation. mBio 2012, 3, e00204-12. [CrossRef] [PubMed]

53. Gardner, M.J.; Bishop, R.; Shah, T.; de Villiers, E.P.; Carlton, J.M.; Hall, N.; Ren, Q.; Paulsen, I.T.; Pain, A.; Berriman, M.; et al Genome sequence of Theileria parva, a bovine pathogen that transforms lymphocytes. Science 2005, 309, 134-137. [CrossRef]

54. Jones, D.T.; Taylor, W.R.; Thornton, J. The rapid generation of mutation data matrices from protein sequences. Bioinformatics 1992, 8, 275-282. [CrossRef]

55. Saitou, N.; Nei, M. The neighbor-joining method: A new method for reconstructing phylogenetic trees. Mol. Biol. Evol. 1987, 4, 406-425. [CrossRef]

56. Kumar, S.; Stecher, G.; Tamura, K. MEGA7: Molecular evolutionary genetics analysis version 7.0 for bigger datasets. Mol. Biol. Evol. 2016, 33, 1870-1874. [CrossRef] [PubMed] 